\title{
Artelogie
}

Recherche sur les arts, le patrimoine et la littérature de l'Amérique latine

$13 \mid 2019$

Violeta Parra: authenticité, primitivisme et processus d'exotisme chez les artistes latino-américains.

\section{La vida y la muerte: Intertextualidad y representación de lo femenino en dos mujeres homenajeadas por Violeta Parra.}

Life and death: Intertextuality and representation of the feminine in two women honored by Violeta Parra.

Lorena Valdebenito Carrasco

\section{OpenEdition}

\section{Journals}

\section{Edición electrónica}

URL: http://journals.openedition.org/artelogie/2898

DOI: $10.4000 /$ artelogie.2898

ISSN: 2115-6395

Editor

Association ESCAL

Referencia electrónica

Lorena Valdebenito Carrasco, « La vida y la muerte: Intertextualidad y representación de lo femenino en dos mujeres homenajeadas por Violeta Parra. », Artelogie [En línea], 13 | 2019, Publicado el 07 enero 2019, consultado el 01 mayo 2019. URL : http://journals.openedition.org/artelogie/2898 ; DOI :

$10.4000 /$ artelogie.2898

Este documento fue generado automáticamente el 1 mayo 2019.

Association ESCAL 


\section{La vida y la muerte: Intertextualidad y representación de lo femenino en dos mujeres homenajeadas por Violeta Parra.}

Life and death: Intertextuality and representation of the feminine in two women honored by Violeta Parra.

Lorena Valdebenito Carrasco

\section{Introducción.}

1 El homenaje en la música, es un recurso propio de los compositores o creadores para ensalzar o valorar a otro personaje que resulta significativo para el creador, y por lo tanto digno de admirar.

2 Sabemos que varias de las canciones escritas por Violeta Parra, nacen a propósito de un vínculo con otras personas. En este sentido, Violeta Parra solía escribir canciones de homenaje cuando sentía admiración por alguna persona, como es el caso de la canción "Los manteles de Nemesio", dedicada al pintor Nemesio Antúnez1; el esquinazo "El día de tu cumpleaños", dedicada a Enrique Bello²; o la pieza instrumental "El joven Sergio", dedicada al fotógrafo Sergio Larraín ${ }^{3}$. Pero también lo hacía para demostrar algún tipo de desdén por alguien, como en la canción "El Albertío", con un texto que podría ser considerado como sarcástico, dedicado a Alberto Zapicán", o, "La muerte con anteojos" dedicada al pintor Julio Escámez 5 .

La lista podría seguir, y podríamos encontrarnos con más canciones dedicadas a personajes masculinos, sin embargo, queremos enfocarnos en aquellas que fueron dedicadas a mujeres; y aquí, la lista parece menos extensa. Pocas fueron las canciones que Violeta Parra escribió a partir de algún vínculo con otras mujeres. De acuerdo con esto, podemos citar las siguientes canciones que escribe con un sentido maternal: 

donde el motivo del homenaje aparece de un modo distinto en cada caso. En el primer caso, se trata de un homenaje musical tras la muerte de Gabriela Mistral, en 1957. Mientras que en el segundo caso, se trata de un homenaje en vida, a la cosmonauta rusa Valentina Tereshkova, en 1963. Dos mujeres importantes, que proviniendo de mundos muy diferentes, como lo son la literatura y la ciencia, su condición de mujer se torna un motivo valioso para ser escogidas por Violeta Parra para rendirle estos homenajes.

11 La distinción fundamental que notamos en estas dos instancias que motivan el acto creativo de Violeta, al homenajear desde la vida y la muerte, puede considerarse un guiño de Parra a dos temáticas fundamentales dentro de la cultura campesina: "lo humano y lo divino"9. Ello se advierte tanto en la poética de las canciones, como también en cuanto a la evocación musical y sonora desde la autoría de cantora y cantautora, en Parra ${ }^{10}$. En este sentido, Torres (2004), destaca que el canto de Violeta puede enmarcarse dentro de varios ejes, analizando en su propuesta tres de ellos: el mundo, lo humano y lo divino, donde: “ La condición humana y sus asuntos más trascendentes, tiene un registro dramático en el continuum vida-muerte" (Torres, 2004: 64). Así, podríamos decir que los temas acerca de la vida y la muerte serían una suerte de fundamento dentro de su propuesta artística, como se advierte en las Décimas (1970) y en varias de sus canciones ${ }^{11}$.

12 Por un lado, el homenaje a propósito de la muerte es directo, donde el lenguaje metafórico se propone ensalzar la figura de Mistral, con un énfasis autoral de Parra, de cantora, debido al uso del recurso a lo poeta; desde lo musical y literario. Por otro lado, en el homenaje en vida a Tereshkova, es críptico. Aquí, la metáfora es una aliada estética usada para hacer críticas sociales, políticas e institucionales, perfilándose un homenaje no evidente del "texto literario" (González, 2016: 17). El homenaje en este caso funciona como un medio, siendo la figura de Tereshkova un excelente pretexto para exponer una serie de problemáticas de corte social y político, donde la voz de Parra es la de una cantautora, con reminiscencias formales y sonoras provenientes del canto a lo poeta.

\section{Perspectivas teóricas y metodológicas.}

13 El uso del texto como elemento base para el análisis -a partir de un objeto de estudio- es una herramienta con una base interdisciplinar. Si bien el concepto de intertextualidad parte desde el campo de la literatura, principalmente desde las propuestas de Julia Kristeva (2001) y Barthes (1984), un texto no es solamente literario, sino todo campo de signos que diga algo, donde "leer es hacer trabajar nuestro cuerpo [...] siguiendo la llamada de los signos del texto, de todos esos lenguajes que lo atraviesan y que forman una especie de irisada profundidad en casa frase" (Barthes, 1984: 38). Es así como desde el 
texto emerge un mundo de significados y "lenguajes" pre-existentes que adquieren un nuevo valor desde la interpretación, cuyo inicio no debiese ser buscado, ya que el texto existe en un espacio cultural cargado de múltiples cruces y sentidos, no siendo posible conocer el origen de su base más primigenia:

La intertextualidad en la que está inserto todo texto, ya que él mismo es el entretexto de otro texto, no debe confundirse con ningún origen del texto: buscar las fuentes, las influencias de una obra es satisfacer el mito de la filiación, las citas que forman un texto son anónimas, ilocalizables y, no obstante, ya leídas antes: son citas sin entrecomillado (Barthes, 1984: 78).

Desde la música, González (2016), propone seis textos posibles para un análisis de la canción popular a partir de una "escucha intertextual" (González, 2016: 17). El texto musical (basado en el lenguaje musical armónico/melódico/rítmico, etc.); el texto sonoro (basado en elementos relacionados con el resultado sonoro de la producción musical, como la mezcla, el uso de recursos tecnológicos, uso de sonidos, etc.); el texto literario (aludido a la dimensión lírica de la canción), el texto performativo (relacionado con la puesta en escena y el uso del cuerpo); el texto visual (basado en el uso del videoclip, $u$ otro recurso visual); y por último el texto discursivo (relacionado con lo que se ha dicho acerca la canción analizada, autor, contexto, etc., y que ayuda a comprender mejor la canción).

En este caso, tomaremos dos dimensiones de los textos propuestos por González (2016) para analizar nuestros ejemplos. Uno es el texto musical, y el otro, es el texto literario. Nos interesa analizar y describir la forma en que ambos textos dialogan desde un plano intertextual, tomando este concepto como eje teórico/metodológico, desde la noción de transtextulidad de Genette (1989). En este sentido, lo transtextual se entiende como un complejo de textos que podrían estar inter-relacionados desde cinco posibles categorías transtextuales: a). La intertextualidad; b). La paratextualidad; c). La metatextualidad; d). La hipertextualidad; y por último, e). La architextualidad (Genette, 1989).

De todas estas posibles maneras en que se evidencia la transtextualidad en un o unos textos, nos parece pertinente asumir la "intertextualidad" en términos genéricos, definida por su autor como una "relación de co-presencia entre dos o más textos, es decir, eidéticamente y frecuentemente como la presencia efectiva de un texto en otro texto" (Genette, 1989: 10).

17 La intertextualidad, desde su noción menos explícita, y ahora más específica, sería, "la alusión", que consiste en "un enunciado cuya mera comprensión supone la percepción de su relación con otro enunciado al que remite necesariamente tal o cual de sus inflexiones" (Genette, 1989: 10), permitiéndonos analizar diferentes aspectos enunciativos en los textos en las canciones.

18 En nuestros ejemplos, la categoría de lo divino ${ }^{12}$ y lo femenino son elementos alusivos base, que dialogan, se dibujan y desdibujan, en función del contenido del texto literario, a partir de diferentes énfasis.

19 Por su parte, el texto musical presenta alusiones que dan sentido al texto literario, cobrando relevancia el uso de varios elementos constructivos (ritmo, melodía, armonía y forma) y expresivos (timbre, sobre todo en el uso de la voz, agógicas y dinámicas).

20 El concepto de "representación" nos permite analizar cómo se muestra, o bajo qué códigos culturales aparece la categoría de lo femenino en las canciones. El concepto de representación asumido desde Hall, sería "un proceso por el cual los miembros de una cultura usan el lenguaje (ampliamente definido como un sistema que utiliza signos, 
cualquier tipo de signos) para producir sentido" (1997: 42). La producción de sentido acerca de lo femenino se constituye entonces en la base de nuestro análisis, a partir de lo que muestra o esconde el texto literario y musical, siendo significado y re-significado.

Lo femenino desde una perspectiva de género, nos invita a poner atención al modo en que aparecen las alusiones sobre los modos de ser mujer (Butler, 2007), en la voz poética y musical de Violeta. Partiendo de la base que lo femenino ha sido cuestionado como categoría, pues, "ya no parece ser una noción estable" (Butler, 2007), siendo más bien una construcción cultural, pero al mismo tiempo posee una significación variable, en tanto aparece como categoría enunciativa desde un código artístico, lo que permite a Violeta Parra lograr un juego estético sobre su alusión.

Por último, lo divino, como una segunda categoría de análisis, es también tratada como una representación en las canciones, produciéndose un diálogo intertextual entre la condición de lo femenino y ciertos componentes místico/religiosos, sobre los cuales se fundamentan las dos canciones a analizar -como también lo es una parte importante de la propuesta artística de Violeta Parra ${ }^{13}$.

En este sentido, lo divino, se comprende como una categoría amplia que remite a conceptos asociados a lo sagrado, lo mítico, lo mágico, lo místico. Cuestión que se tornará un desafío en este trabajo, considerando que estos conceptos no han sido fáciles de abordar, como se consigna en las siguientes palabras: "lo sagrado en las mujeres atraviesa una revuelta instantánea que atraviesa el cuerpo, y que grita" (Clément, 2000: 18).

Es así como la relación entre "lo femenino y lo sagrado" que encontramos en el interesante diálogo epistolar de Julia Kristeva y Catherine Clément (2000), es discutida desde las representaciones (como concepto transhistórico y transcultural) en múltiples figuras femeninas (la virgen María, Medea, Eva Perón, Isolda, Diana de Gales, la madre Teresa de Calcuta, entre muchas otras), quedando abierta la interrogante acerca de los significados culturalmente cristalizados y totalmente discutibles, situados en medio de una tensión epistemológica feminista aún no resuelta.

\section{Homenaje en vida a Valentina Tereshkova: "Ayúdame Valentina" (1971).}

El disco póstumo, "Canciones reencontradas en Paris" (1971), es un trabajo con un contenido político y combativo, después del disco "Toda Violeta Parra" (1961), que ha sido considerado por González (2018), como el primer disco autoral de Violeta Parra, pues a partir de esta producción, Violeta incorporaría más canciones de su autoría que en discos anteriores $^{14}$.

El texto literario que encontramos en la canción "Versos por despedida a Gabriela Mistral" (que analizaremos más adelante), es directo en el contexto del homenaje, y por esto mismo contrasta con el texto de la canción "Ayúdame Valentina", que presenta una mayor cantidad de alusiones que complejizan la relación intertextual que se da al interior de la canción, no siento evidente la intención del homenaje.

Para, Torres (2004), en el verso: “¿Qué vamos a hacer con tanto/ tratado del alto cielo?/ Ayúdame Valentina'! ya que tú volaste tan lejos.! Dime de una vez por todas/ que arriba no hay tal mansión:/ mañana la ha de fundar/ el hombre con su razón", Violeta Parra se 
rebela "contra la manipulación oscurantista de la verdad, reivindica la mirada desmitificadora de la ciencia" (Torres, 2004: 66). podría ser un bombo o un kultrún, en una métrica de $4 / 4$, donde la austeridad instrumental se advierte en la percusión y el uso de la voz que comienza en el segundo momento de la canción. En este primer momento, la percusión solitaria evoca una atmósfera ritual, considerando la percusión ${ }^{15}$ :

Figura № 1: Introducción canción "Qué vamos a hacer"

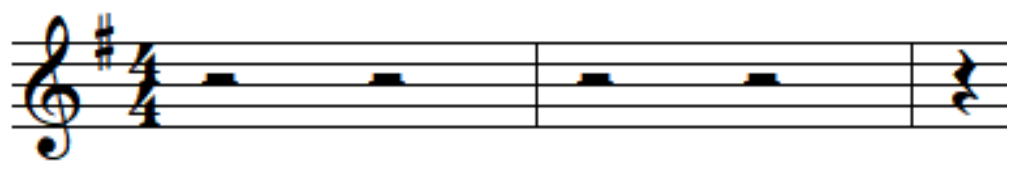

\section{El segundo momento.}

El segundo momento está marcado por la voz de una Violeta enfática que inicia con el verso "Qué vamos a hacer", siendo desarrollado como una interrogante durante toda la canción, con dinámicas de intensidad de plano que se advierten sobre todo en los tiempos fuertes para enfatizar el texto. 


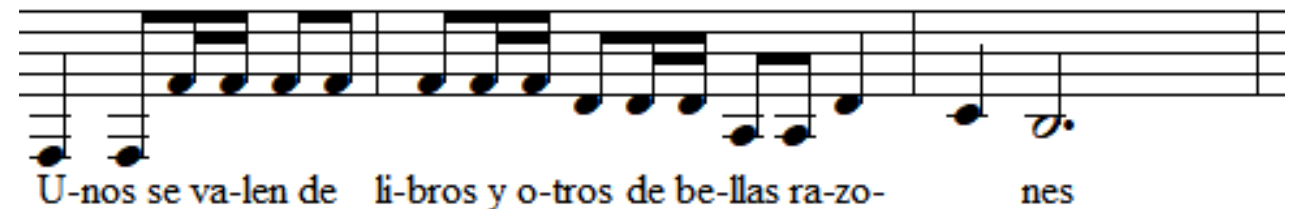

\section{Tercer momento}

El uso de las células rítmicas formadas por saltillos y corcheas dobles, le otorgan agilidad al discurso lírico y musical. El uso de una melodía lúdica y a veces pendular, que se desarrolla entre intervalos de quintas, terceras y segundas, alude en su texto literario una serie de recursos empleados por los predicadores que se presentan dentro de una gran frase interrogativa, usando para ello el IV grado, para concluir en la tónica al final del verso.

Figura Nº 4: Fragmento canción “Qué vamos a hacer” 


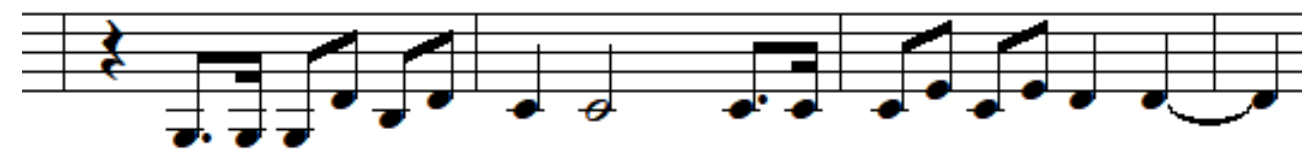

Al-gu-nos de cuen-tos va- rios mi- la-gros y a-pa-ri-cio-nes

Figura N 5: Fragmento canción “Qué vamos a hacer"

$40 \quad$ IV

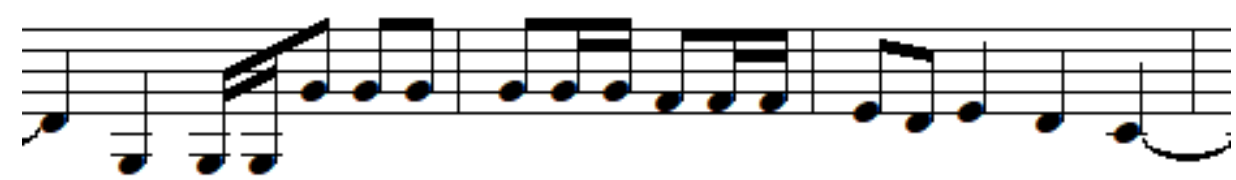

yal-go-tros de la pre- sen- ciade es-que-le-tos es-cor-pio-nes

Figura Nº 6: Fragmento canción “Qué vamos a hacer"

$41 \quad$ V7 I

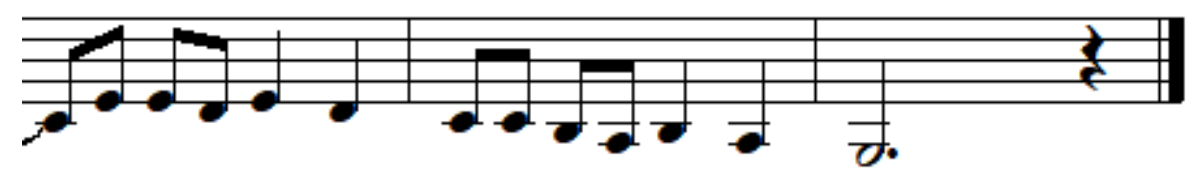

ma-mi-ta mi- ay los es-cor-pio- nes

42

43 


\begin{tabular}{|c|c|}
\hline $\begin{array}{l}\text { Qué vamos a } \\
\text { hacer con } \\
\text { tantos } \\
\text { y tantos } \\
\text { predicadores. } \\
\text { Unos se valen } \\
\text { de libros } \\
\text { y otros de } \\
\text { bellas razones, } \\
\text { algunos de } \\
\text { cuentos varios, } \\
\text { milagros } \\
\text { apariciones } \\
\text { y algotros de la } \\
\text { presencia } \\
\text { de esqueletos y } \\
\text { escorpiones, } \\
\text { mamita mida, } \\
\text { y los } \\
\text { escorpiones. }\end{array}$ & $\begin{array}{l}\text { La categoría de lo divino, se expone como una duda a lo largo de la canción. } \\
\text { Primero comienza dudando de los predicadores, quienes usan diferentes } \\
\text { artilugios para convencer a los fieles. } \\
\text { La alusión a lo femenino, aparece a lo largo de toda la canción, siendo dirigida a } \\
\text { Valentina Tereshkova. Esta alusión escogida por Violeta, es la de una } \\
\text { conversación que tiene imaginariamente con Valentina, siendo de algún } \\
\text { modo, interrogada e invitada a reflexionar acerca de varias problemáticas } \\
\text { sociales, políticas y religiosas. } \\
\text { Valentina, en la canción, es la voz femenina de la ciencia, a quien acude } \\
\text { Violeta Parra precisando ayuda para responder a diferentes temas desde su } \\
\text { expertise. } \\
\text { Con este gesto, Violeta, no quiere estar sola, tanto en la crítica como en la } \\
\text { acción. ¿A quién escoge? A una igual. Primero, Valentina es una mujer. Luego, } \\
\text { una mujer campesina que se transforma en una autoridad científica: la } \\
\text { primera mujer que viaja al espacio, y lo hace sola. } \\
\text { Sin embargo, no es sino hasta la quinta estrofa de la canción donde Valentina } \\
\text { comienza a ser aludida de un modo particular: “Qué vamos a hacer?”, } \\
\text { “Ayúdame Valentina", “Apúrate Valentina". }\end{array}$ \\
\hline $\begin{array}{l}\text { Qué vamos a } \\
\text { hacer con tanta } \\
\text { plegaria sobre } \\
\text { nosotros, } \\
\text { que alega en } \\
\text { todas las } \\
\text { lenguas } \\
\text { de gloria y esto } \\
\text { que lo otro, } \\
\text { de infiernos y } \\
\text { paraísos, } \\
\text { de limbos y } \\
\text { purgatorios, } \\
\text { edenes y vida } \\
\text { eterna, } \\
\text { arcángeles y } \\
\text { demonios, } \\
\text { mamita mida, } \\
\text { y con los } \\
\text { demonios. }\end{array}$ & $\begin{array}{l}\text { En esta estrofa, Violeta Parra, duda de quienes tienen creencias doctrinales, } \\
\text { como el infierno y el paraíso, el limbo y el purgatorio, el Edén y la vida eterna, } \\
\text { los arcángeles y demonios. Como así de quienes tienen una fe genuina, } \\
\text { ejercida a través de sus plegarias. }\end{array}$ \\
\hline
\end{tabular}




\begin{tabular}{|c|c|}
\hline $\begin{array}{l}\text { Que sí, que } \\
\text { adoren la } \\
\text { imagen } \\
\text { de la señora } \\
\text { María, } \\
\text { que no se adore } \\
\text { ninguna } \\
\text { señora } \\
\text { señorita, } \\
\text { que sí, que no, } \\
\text { que mañana, } \\
\text { que un viernes } \\
\text { de amanecida, } \\
\text { que pa' dentrar } \\
\text { a la gloria } \\
\text { dinero } \\
\text { necesita, } \\
\text { ay, mamita } \\
\text { mida, } \\
\text { y se necesita. }\end{array}$ & $\begin{array}{l}\text { En esta estrofa, Parra, cuestiona el sentido de la adoración de quiénes se dicen } \\
\text { ser creyentes, en relación con la virgen María. Esta duda sobre la necesidad de } \\
\text { adorar a la virgen como figura sagrada, es una alusión que Parra aprovecha } \\
\text { muy bien para interpelar el orden religioso institucional, tal como lo hace } \\
\text { Kristeva (2000), treinta y cuatro años después que Violeta. La autora } \\
\text { feminista, discute acerca de los límites del dogma en la progresiva legitimidad } \\
\text { de María, cuando señala que: "Todas estas sutilezas a las que será sometido el } \\
\text { cuerpo de María se imponen sin embargo muy lentamente como dogma [...] el } \\
\text { dogma de la Inmaculada Concepción, data de 1854, el de Asunción de la } \\
\text { Virgen... de 1950 [...] sólo fue proclamada reina en 1954, por Pío XII, y es } \\
\text { madre de la Iglesia solamente desde 1964" (Kristeva, 2000: 100-101). } \\
\text { Parra, luego enlaza esta "legitimidad" de la virgen María, con otra antigua } \\
\text { "legitimidad" católica; la creencia sobre las indulgencias y el precio de la } \\
\text { salvación: "que pa' dentrar en la gloria dinero se necesita". }\end{array}$ \\
\hline $\begin{array}{l}\text { Se ve que no } \\
\text { son muy } \\
\text { limpios } \\
\text { los trigos en } \\
\text { esta viña } \\
\text { y la cizaña } \\
\text { pretende } \\
\text { comerse toda la } \\
\text { espiga. } \\
\text { Poco le dice la } \\
\text { forma } \\
\text { con que hai de } \\
\text { clavar su espina } \\
\text { para chupar el } \\
\text { más débil, } \\
\text { qué diabla la } \\
\text { sabandija, } \\
\text { mamita mida, } \\
\text { la sabandija. }\end{array}$ & $\begin{array}{l}\text { A través de la parábola sobre el trigo y la cizaña en el sermón de la montaña } \\
\text { pronunciada por Cristo (San Mateo 13: 24-30), pone en duda la rectitud de } \\
\text { ciertas personas que no serían del todo buenas, Cristo las llama "enemigos" en } \\
\text { la parábola, siendo más bien desagradables, para Violeta llamándolos en } \\
\text { singular: "diabla la sabandija". }\end{array}$ \\
\hline
\end{tabular}




\begin{tabular}{|c|c|}
\hline $\begin{array}{l}\text { Qué vamos a } \\
\text { hacer con tanto } \\
\text { tratado del alto } \\
\text { cielo, } \\
\text { ayúdame, } \\
\text { Valentina, } \\
\text { ya que tú } \\
\text { volaste lejos, } \\
\text { dime de una } \\
\text { vez por todas } \\
\text { que arriba no } \\
\text { hay tal } \\
\text { mansión; } \\
\text { mañana la ha } \\
\text { de fundar } \\
\text { ya el hombre } \\
\text { con su razón, } \\
\text { mamita mida, } \\
\text { y con su razón. }\end{array}$ & $\begin{array}{l}\text { Por primera vez, Parra, menciona a Valentina, sin embargo le pide ayuda en } \\
\text { su condición de mujer de ciencia, dudando de la creencia acerca de la } \\
\text { existencia del cielo, echando por tierra la idea de que existe realmente una } \\
\text { mansión, estableciendo con esto una antítesis entre fe y razón. }\end{array}$ \\
\hline $\begin{array}{l}\text { Qué vamos a } \\
\text { hacer con } \\
\text { tantos } \\
\text { y embajadores } \\
\text { de dioses. } \\
\text { Me salen a cada } \\
\text { paso } \\
\text { con } \\
\text { colmillos } \\
\text { feroces. } \\
\text { Apúrate, } \\
\text { Valentina, } \\
\text { que } \\
\text { aumentaron los } \\
\text { pastores, } \\
\text { porque ya viene } \\
\text { el derrumbe } \\
\text { del cuento de } \\
\text { los sermones } \\
\text { mamita mida, } \\
\text { y de los } \\
\text { sermones. }\end{array}$ & $\begin{array}{l}\text { Violeta, duda de los dirigentes religiosos, cuestionando su legitimidad como } \\
\text { líderes, no tanto de "Dios", sino de lo que serían "dioses", vale decir, líderes } \\
\text { que podrían tener una fe pagana, condición simbolizada con una metáfora } \\
\text { extrema, pues, Violeta, los ve con "colmillos feroces". }\end{array}$ \\
\hline
\end{tabular}




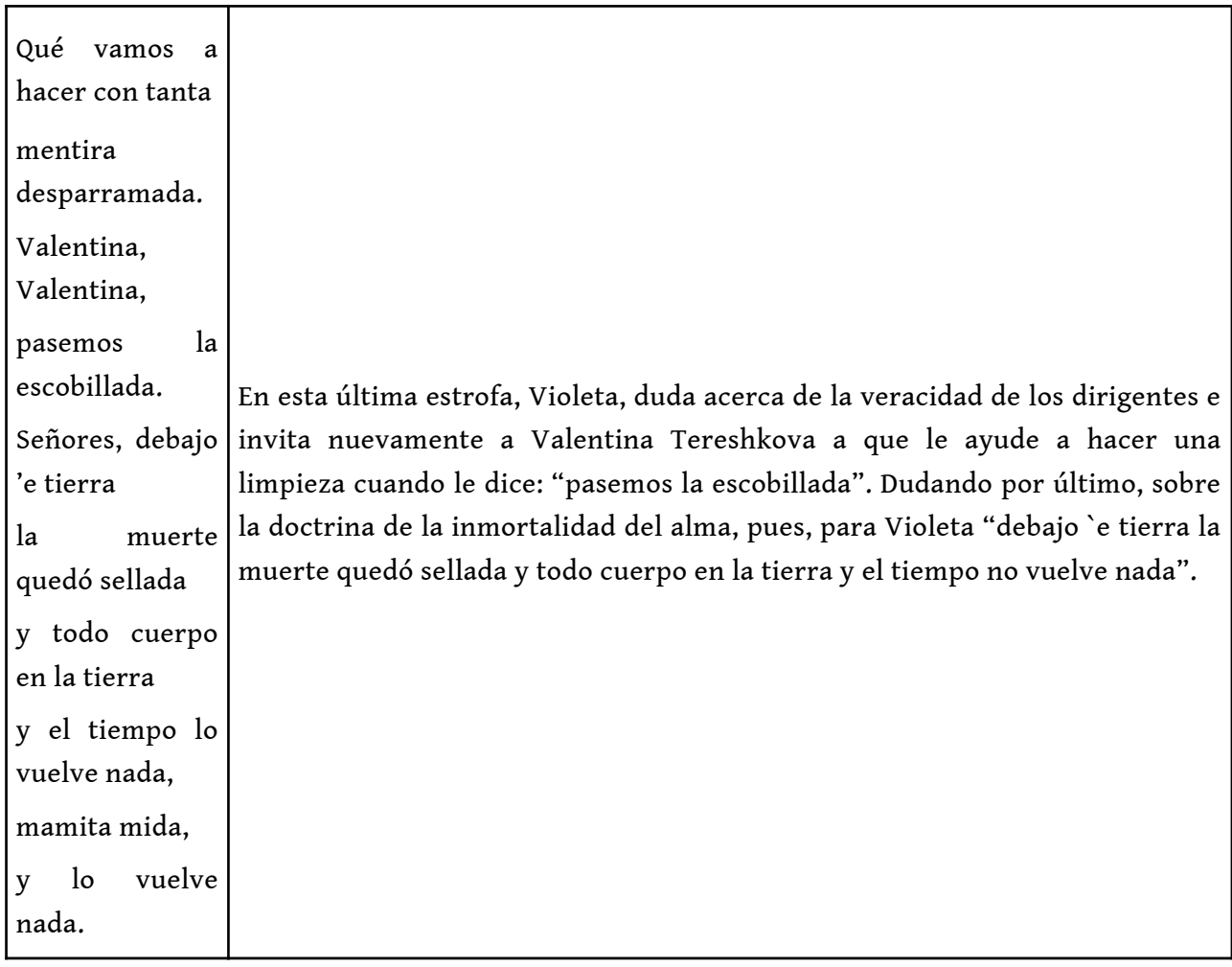

\section{Homenaje a partir de la muerte de Gabriela Mistral: "Versos por despedida a Gabriela Mistral" (1957).}

Los homenajes post-mortem, fueron usados en dos oportunidades por Violeta Parra, en estilo a lo poeta, y convertidos en canciones. Uno a Gabriela Mistral, y otro dedicado a su hija Rosita Clara, en "Versos por la niña muerta" (1957). Luego que Violeta muere, su amigo Héctor Pavez, le rinde un homenaje en el mismo estilo, titulado "Adiós querida Violeta" (1967), siendo éste una especie de legado musical de Violeta, pues normalmente en la tradición campesina, la música dedicada a la muerte se hace en contextos de funerales a niños pequeños, llamados angelitos. Parra, en su homenaje a Mistral, señala que se trata de un "canto a lo divino".

A modo de referente, una de las interpretaciones acerca del homenaje de Parra a Mistral, es la que encontramos en la tesis doctoral de Ariz (2013). Trabajo que trata sobre diversas poéticas integradas, en una interesante relación entre cuatro destacadas mujeres artistas chilenas: Gabriela Mistral, Violeta Parra, Cecilia Vicuña y Soledad Fariña.

La perspectiva de Ariz (2013), apunta a los fundamentos de "lo humano y lo divino", propios de la lira popular, y a las estrategias literarias en la poética del texto. Su análisis se centra en los elementos simbólicos y metafóricos que emanan del texto, notando profundos sentidos desde el plano poético, pero también argumentativos; esta vez, desde un plano discursivo, que se perfila a través del pliegue que aparece en el estereotipo del personaje de Mistral, visto desde Parra.

Para ampliar este interesante análisis literario de Ariz (2013), queremos hacerlo desde el "texto musical" y el "texto literario"; dos categorías propuestas por González (2016: 17), 
para establecer un recorrido dialógico entre el sonido/música y la representación de lo femenino en la canción.

51 A pesar de ser un hecho evidente, nos parece oportuno destacar el elemento mitificador que aparece en el homenaje de Parra a Mistral, pues, ésta es una cuestión crucial para apreciar cómo se desarrolla la representación de lo femenino en la canción. En este sentido, la mitificación proyecta una representación idealizada de la figura homenajeada, que incide en la representación de lo femenino de Gabriela Mistral, que Ariz (2013), distingue como un trayecto de Mistral en la canción de Parra, desde la figura más lejana a la más cercana: "Diosa", "Presidenta", "Santa" y "madrina" (Ariz, 2013 : 624).

Estas cuatro categorías de lo femenino, se entrecruzan para lograr la mitificación de Mistral, donde lo intelectual se presenta en la elección del personaje a homenajear. Una figura que simboliza a la mujer que piensa, que tiene una sólida perspectiva social y política, tomando en cuenta a Edward Saíd en esta manera de entender al, o a la intelectual, cuya figura es definida como "un individuo dotado de la facultad de representar, encarnar y articular un mensaje, una visión, una actitud, una filosofía o una opinión para y en favor de su público" (Saíd, 2007: 30).

Pero luego, lo intelectual en la canción, se re-direcciona, cuando se potencia lo femenino, incorpóreo y divino de Mistral, destacado desde una dimensión espiritual.

Es aquí donde la razón -representada en la dimensión intelectual del personaje- y la fe representada en la dimensión mística de Gabriela como una "santa"-, dos categorías que históricamente han sido significadas como opuestas ${ }^{16}$, entran en una dinámica intertextual aludidas en la voz de Violeta Parra como "performer", según lo entiende Moore (2012: 180-181).

Otro interesante aspecto intertextual que podemos notar, y que apunta a un plano si se quiere más global, es el que se da en la propuesta estético-musical de Violeta, es decir, el uso de la tradición campesina para hacer su homenaje, y la perspectiva que Mistral tiene sobre el folclore y la tradición. Para Mistral, el folclore es una cuestión primordial dentro de la cultura, con un énfasis latinoamericanista, muy propio de la época:

"Hay un misterio en el folklore, que es el misterio de la voz genuina de una raza, de la voz verdadera y de la voz directa, y es que en él se canta la raza por sí misma, no se canta por esa especie de altoparlante tan dudosa que es el poeta o es el novelista. El folklore se parece a la entraña. No se puede nadie acercar al folklore con un pensamiento demasiado estético. Las entrañas no son bonitas, son bastante feas; pero tienen la primera categoría en el organismo. Todo lo demás existe como adorno de ella.

El folklore tiene esa fealdad de las entrañas y la fealdad de las fraguas y del motor miradas por dentro" (Mistral, En: Esteban, 1978: 324).

La distinción que Mistral hace entre la "estética", asumida como la manera en que se valida lo bello desde la academia basada en el canon europeo, y el folclore, que sería feo como una entraña, es vital, pues su valoración se convierte en una condición trascendente que permite legitimar un espacio, un modo de vida, un saber que según la poetisa, no debiese ser valorado desde el pensamiento estético occidental.

En este sentido, la muerte, instancia sobre la cual Gabriela es homenajeada por Violeta Parra, dialoga en su expresión más esencial con el folclore, valorado por Mistral como un fenómeno de "primera categoría". Aquí, la figura de Mistral alcanza una doble condición trascedente: cuando según Violeta Parra, pasa a ser "santa", pero además siendo el 
folclore la expresión más importante de la cultura, su homenaje posiciona a Mistral en un espacio de valoración por lo que aquella expresión representa.

En "Versos por despedida a Gabriela Mistral", se hace difícil señalar los momentos de la pieza, pues, al parecer se trata de un único y gran momento, como si fuese una estrofa de largo aliento, muy propio del canto a lo poeta, donde la métrica del verso en décimas se constituye en la base rítmica de la melodía que resulta reiterativa. El primer y segundo verso, en términos melódicos, es similar al quinto, sexto, octavo y décimo verso. Luego el tercer y cuarto verso es similar melódicamente al séptimo y octavo verso. La base armónica descansa en un solo cambio que va de tónica (I) a dominante con séptima (V7) en tonalidad de Do Mayor, que se logra desde una guitarra traspuesta, afinada en:

El acorde de Do Mayor se emite ejecutando las cuerdas de la guitarra al aire. Según Andreu (2017), esta afinación corresponde a la denominada "Por Transporte", normalmente usada en Valdivia.

Usando esta afinación como base, la melodía vocal comienza con un intervalo de sexta ascendente. Violeta, da inicio a la canción, siendo cada vez menos amplios los intervalos que componen el perfil melódico como se puede apreciar en la imagen; intervalos de una cuarta descendente y de segundas mayores que se mueven pendularmente para concluir en la tónica, usando el V7 para enfatizar el inicio del siguiente verso:

Figura № 7: Fragmento canción “Versos por despedida a Gabriela Mistral"

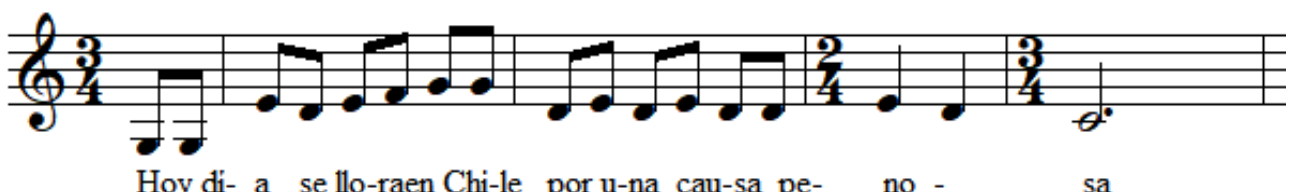

El tercer y cuarto verso, parece ser una respuesta en términos melódicos o un consecuente en estilo recitado, donde la variación melódica de esta sección es mínima, vale decir, con una distancia de una segunda mayor, de un Do a un Re, lo que le da un aire sacro, considerando lo sacro con reminiscencias al estilo del canto llano, cuyo texto lírico refiere al llamado de Dios a Mistral al cielo.

Figura N 8: Fragmento canción "Versos por despedida a Gabriela Mistral" 


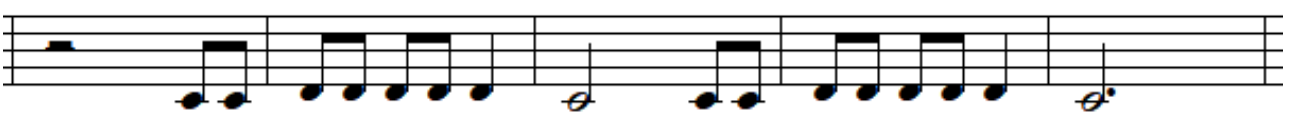

Dios ha lla-ma-doa laDio- sa a su man- sión tan su-bli- me

70 Como señalamos más arriba, notamos que el tercer verso y cuarto son similares al primero y segundo en términos melódicos, sin embargo el texto lírico varía en su desarrollo temático, pues, ahora alude a la costumbre del velorio de los difuntos en términos concretos:

Figura N 9: Fragmento canción "Versos por despedida a Gabriela Mistral"

$71 \quad$ I I

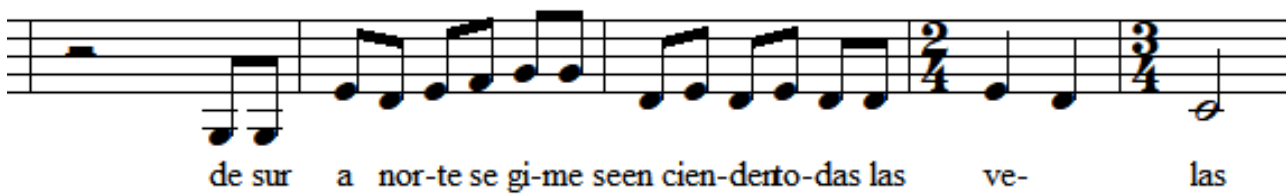

72 En el cuarto verso, nuevamente se advierte una melodía que varía mínimamente entre las notas, Re y Do. Esta vez, el texto alude a la luz de las velas que alumbran a Gabriela, y más específicamente a la muerte simbolizada por la sombra, a través de esta melodía que parece ser un rezo:

Figura N 10: Fragmento canción "Versos por despedida a Gabriela Mistral"

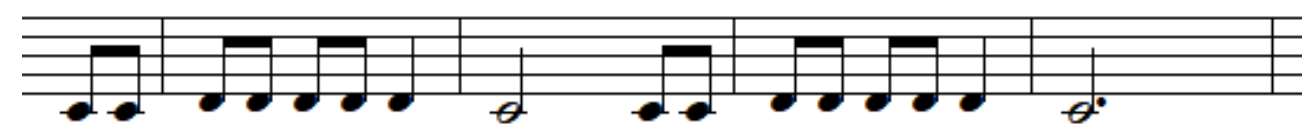

pa-raa-lum- brar-lea Ga-brie-la

la som-bra quehoy es su mu- do

Figura № 11: Fragmento canción “Versos por despedida a Gabriela Mistral”

$74 \quad$ I I V7

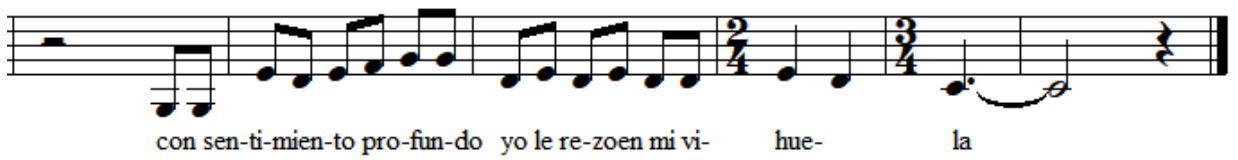

Una de las formas en que se valida el pensamiento de un/una autora, es la revisión de su perspectiva sobre un tema determinado a lo largo de su obra.

En este sentido, la muerte se transforma en una posibilidad real de concreción; una certeza, una verdad, tal y como Violeta Parra lo expone en su canción "Run, run se fue pa'l norte": que la vida es mentira, que la muerte es verdad. La idea de la muerte como verdad o como certeza puede ser comprendida desde el punto de vista de su suicidio, pero también desde el punto de vista de lo que la muerte significa para Violeta en su relación 
con una creencia religiosa, es decir, la muerte como fenómeno humano que sensibiliza la fe de los creyentes, en este caso de Violeta, cuando manifiesta una certeza de paz, de trascendencia y de salvación después de la muerte.

Mientas lo divino en "Qué vamos a hacer" (Ayúdame Valentina) aparecía como duda, en "Versos por despedida a Gabriela Mistral" (1957) podemos notar dos claras temáticas intertextuales, en el contexto de la muerte:

a. Lo divino aparece como creencia de fe o certeza (en el homenaje por la muerte)

b. Lo femenino aparece como figura idealizada e incorpórea

Según como vemos en la siguiente tabla:

Tabla № 2: Análisis Texto Literario

\begin{tabular}{|c|c|}
\hline Texto Literario & Énfasis del Texto Literario \\
\hline $\begin{array}{l}\text { Hoy dida se } \\
\text { llora en Chile } \\
\text { por una causa } \\
\text { penosa: } \\
\text { Dios ha llama'o } \\
\text { a la diosa } \\
\text { a su mansión } \\
\text { tan sublime. } \\
\text { De sur a norte } \\
\text { se gime, } \\
\text { se encienden } \\
\text { to'as las velas } \\
\text { para } \\
\text { alumbrarle a } \\
\text { Grabiela } \\
\text { la sombra que } \\
\text { hoy es su } \\
\text { mundo. } \\
\text { Con } \\
\text { sentimiento } \\
\text { projundo } \\
\text { yo le rezo en } \\
\text { mi vihuela. }\end{array}$ & $\begin{array}{l}\text { Lo femenino en la canción se perfila como una temática que dialoga con el } \\
\text { personaje de Mistral. ¿Quién es Gabriela Mistral? Desde el punto de vista de lo } \\
\text { que representa como figura; es una mujer intelectual que se ha posicionado en } \\
\text { un espacio eminentemente masculino, desde su condición de poeta o artista, } \\
\text { pero Mistral es también una mujer que tiene una posición clara y crítica frente } \\
\text { temas políticos y sociales con un énfasis latinoamericanista, muy propio de la } \\
\text { época de los años } 40 \text { y } 50 \text { en Chile. Una mujer que proviene del mundo rural } \\
\text { que va construyéndose como una gran figura del arte, recibiendo en 1945, por } \\
\text { primera vez en Chile, el Premio Nobel. } \\
\text { Pero luego, Violeta dibuja una Mistral idealizada en la canción, a propósito de } \\
\text { la muerte. En este primer verso, la muerte como certeza, se advierte en la } \\
\text { existencia de una mansión celestial que acoge a Gabriela Mistral, en un } \\
\text { concepto mítico-religioso. }\end{array}$ \\
\hline
\end{tabular}




\begin{tabular}{|c|c|}
\hline $\begin{array}{l}\text { Presi'enta y } \\
\text { bienhechora } \\
\text { de la lengua } \\
\text { castellana, } \\
\text { la mujer } \\
\text { americana } \\
\text { se inclina la } \\
\text { vista y llora } \\
\text { por la celestial } \\
\text { señora } \\
\text { que ha partí'o } \\
\text { de este suelo. } \\
\text { Yo le ofrezco } \\
\text { sin recelo } \\
\text { en mi canto a } \\
\text { lo divino } \\
\text { que un ave de } \\
\text { dulce trino } \\
\text { la acompañe al } \\
\text { alto cielo. }\end{array}$ & $\begin{array}{l}\text { En este verso, Mistral es considerada como "Presidenta y bienhechora de la } \\
\text { lengua castellana", en su calidad de poetisa, y mujer de letras, para luego hacer } \\
\text { una invitación puntual a un sujeto femenino determinado, vale decir, a "la } \\
\text { mujer americana", a llorar por la partida de Mistral. Cuando el texto literario } \\
\text { de Parra, evoca aquí a otro sujeto femenino a mostrar empatía y condolerse } \\
\text { por Gabriela Mistral, está trayendo al frente la temática de la legitimación } \\
\text { femenina entre mujeres. Asunto que ha tenido importancia dentro de las } \\
\text { perspectivas feministas, como lo es la reivindicación de las mujeres en los } \\
\text { espacios sociales. } \\
\text { El sentido y fundamento del homenaje de Violeta Parra a Gabriela es claro } \\
\text { cuando señala que se trata de que su canto es realmente un "canto a lo divino", } \\
\text { siendo congruente con la alusión sobre de la ascensión de Mistral al cielo. }\end{array}$ \\
\hline $\begin{array}{l}\text { En medio del } \\
\text { paraíso } \\
\text { hay un sillón } \\
\text { de oro fino } \\
\text { y un manto de } \\
\text { blanco lino } \\
\text { que la Virgen } \\
\text { mesma le hizo. } \\
\text { Un ángel de } \\
\text { bellos rizos } \\
\text { está esperando } \\
\text { en la entrá' } \\
\text { a la mejor } \\
\text { invitá' } \\
\text { que ocupará } \\
\text { aquel sillón } \\
\text { hasta } \\
\text { consumación: } \\
\text { Santa Mistral } \\
\text { coroná'. }\end{array}$ & $\begin{array}{l}\text { Mientras en el texto literario de la canción "Ayúdame Valentina", la figura de } \\
\text { la Virgen es un ser que podría ser cuestionado por otros, y por lo tanto puesta } \\
\text { en duda su adoración en un contexto de fe. Ahora Violeta, señala con plena } \\
\text { certeza la importancia de la virgen María, como figura celestial, cuando es ella } \\
\text { quien acoge a Gabriela Mistral, con un "manto de blanco lino que la Virgen } \\
\text { misma le hizo", siendo declarada por Violeta como "Santa Mistral". } \\
\text { De igual modo, mientras en "Ayúdame Valentina", Violeta duda de la } \\
\text { existencia de una mansión celestial o paraíso, ahora éste es un lugar que } \\
\text { realmente existe, pues, es allí donde Gabriela es recibida por la virgen María y } \\
\text { un ángel. }\end{array}$ \\
\hline
\end{tabular}




\begin{tabular}{|c|c|}
\hline $\begin{array}{l}\text { Hay una fiesta } \\
\text { en la gloria } \\
\text { y un llorar } \\
\text { aquí en la } \\
\text { tierra, } \\
\text { como si una } \\
\text { grande guerra } \\
\text { haya mancha'o } \\
\text { la historia. } \\
\text { Jamás } \\
\text { nuestra } \\
\text { memoria } \\
\text { ha } \\
\text { olvidarte, } \\
\text { Gabriela. } \\
\text { Los niños de } \\
\text { las escuelas } \\
\text { ya no tienen su } \\
\text { mairina: } \\
\text { la Provi'encia } \\
\text { Divina } \\
\text { se llevó la flor } \\
\text { más bella. }\end{array}$ & $\begin{array}{l}\text { En esta última estrofa de la canción, Parra, expone a una paradoja a propósito } \\
\text { de la muerte de Mistral; "una fiesta en la gloria y un llorar aquí en la tierra". } \\
\text { Con este enunciado, Violeta evoca uno de los principio alquímicos, llamado } \\
\text { "Principio de correspondencia". Este principio consiste en que "lo que existe } \\
\text { arriba en el macrocosmos, se repite abajo en el microcosmos" (Fernández, } \\
\text { 2010: 22). Existe un evento que es la muerte de Gabriela Mistral, luego este } \\
\text { evento tiene una correspondencia en tanto ocurren hechos asociados a este } \\
\text { evento, sin embargo esa correspondencia no es de carácter inverso bajo el } \\
\text { símbolo de fiesta/llanto. } \\
\text { Así también la muerte de Mistral, es significada como "una grande muerte", es } \\
\text { decir, un hecho doloroso que va ser difícil de olvidar en términos colectivos, } \\
\text { tanto por los adultos en la voz de Violeta "Jamás de nuestra memoria ha de } \\
\text { olvidarte, Gabriela", como por los "niños en las escuelas", quienes "ya no } \\
\text { tienen a su mairina", cuya muerte es asumida por Violeta como un designio de } \\
\text { la "Providencia Divina". La evocación de "mairina" de los niños por parte de } \\
\text { Parra, habla de una nueva categoría femenina, la de madre sustituta o de } \\
\text { madre en reemplazo de la madre verdadera, evitando el concepto de "Madre"17 } \\
\text { y no llegando a sacralizarla desde ese lugar femenino. }\end{array}$ \\
\hline
\end{tabular}

\section{Conclusiones}

81 La ascensión de Valentina Tereshkova al cielo, es un evento simbólico que se convierte en un tópico intertextual vinculado con nuestra categoría de análisis: Lo divino. Así como Valentina asciende al cielo, lugar donde vive Dios, Mistral también lo hace a propósito de su muerte. Si bien, Lo divino, es un atributo masculino, Violeta, lo destaca desde la posibilidad más cercana a una figura divina y femenina que podría existir en el cielo, es decir, la virgen María. Aquí podemos notar cómo lo divino y lo femenino entran en una relación intertextual, en la alusión que encontramos en el relato literario y musical de Parra -mujer cantautora-, sobre Gabriela Mistral -mujer poetisa-, Valentina Tereshkova mujer cosmonauta-, y la virgen María, mujer santa.

82 La virgen como figura femenina, es referenciada en las dos canciones, luego lo femenino como categoría de análisis, demuestra un desplazamiento entre la evocación de mujeres para el homenaje, siendo relevante quiénes son estas mujeres, pero también cómo aparecen representadas en las canciones.

Respecto de quiénes son, podemos notar elementos comunes, pues, tanto Valentina Tereshkova como Gabriela Mistral, tienen un pasado similar entre ellas, y a su vez, éste es similar a la historia de vida de Violeta Parra.

En este sentido, todas tienen ideas asociadas a un pensamiento social y claramente matizado desde un enfoque político de izquierda. Gabriela Mistral, siempre manifestó una inclinación hacia idearios políticos con un énfasis social. Por su parte, Valentina 
Tereshkova militó en el partido comunista desde 1961 a 1991. Y por último, Violeta Parra, siempre mostró una tendencia política de izquierda, y además militó por un tiempo en el partido comunista. Así también, todas tuvieron un origen campesino y posteriormente se transforman en mujeres intelectuales ${ }^{18}$, donde sus quehaceres pudieron ser legitimados en sus diferentes espacios de desarrollo. Es así como Mistral y Tereshkova reciben dos importantes reconocimientos, una el Premio Nobel de Literatura, siendo reconocida su obra como una de las importantes en términos universales. Y la otra, un reconocimiento por ser la primera mujer en viajar al espacio, y una serie de otros reconocimientos por su destacada carrera en el programa espacial soviético.

Si bien Violeta Parra, es mucho más reconocida hoy que en su tiempo; en vida alcanzó a desarrollarse como una excelente músico, grabando once discos, recibiendo una importante distinción por su labor como folclorista, como lo fue el Premio Caupolicán, en 1954, y realizando una importante exposición de su trabajo visual en el Museo de Artes de Decorativas en Paris, en 1964.

Luego respecto de cómo aparecen representadas estas mujeres, podemos decir que la muerte como evento desde el cual Violeta Parra, rinde su homenaje a Gabriela Mistral, nos permite advertir un perfil femenino mucho más sensible e idealizado, siendo aludida entre nominaciones de excelencia, como: Diosa, Profesora, Presidenta, Santa y madrina, siempre en un contexto mitificador.

Por su parte, Valentina Tereshkova aparece representada como una mujer inteligente, una interlocutora legitimada por Violeta Parra para establecer un diálogo profundo sobre diferentes problemáticas de corte político, religioso e institucional, con quien reflexiona, de quien espera respuestas y a quien solicita ayuda.

La intertextualidad musical se logra desde los elementos comunes del lenguaje musical o estético que usa Violeta en las canciones analizadas, nos referimos a que ambas son elaboradas con un lenguaje proveniente de la tradición campesina, perfilando la autoría de una Violeta Cantora/Cantautora (uso de la guitarra traspuesta, uso de la décima, uso del canto a lo divino).

La aparente contradicción que existe entre la certeza (en relación con la muerte) y la duda (en relación con la vida) en las canciones, demuestra un desplazamiento en la voz autoral de Violeta Parra, siendo posible la narración de realidades y modos de pensar a través de juicios y lecturas críticas sobre el mundo de la vida y la muerte. En este contexto, la canción además de ser poesía cantada, se transforma en un espacio donde el decir es efectivo, donde el arte ocupa un lugar de enunciación rico en múltiples significados. Un espacio donde las creencias son reemplazadas por las dudas, y las dudas por las creencias. La música es el canal artístico que permite ubicar en un contexto musical, diferentes niveles de diálogo entre un texto e intertexto, como también modos antagónicos de decir "verdades", a partir de diferentes reflexiones en lo aludido, tanto en lo literario como en lo musical. Así, lo divino y lo femenino en estas dos canciones analizadas, se encuentran y desencuentran como dos categorías deferentes dentro de un mismo fenómeno musical: el homenaje en la canción de autor/a. 


\section{BIBLIOGRAFÍA}

ANDREU, Andrea (2017), Visión comparativa de las afinaciones de la guitarra tradicional en Chile, Perú y Argentina, Tesis para optar el grado académico de Magíster en Artes Musicales Mención Cultura Tradicional, Universidad Mayor, Santiago de Chile.

ARIZ, Yenny (2013), Gabriela Mistral, Violeta Parra, Cecilia Vicuña y Soledad Fariña: Poéticas de las artes integradas Tesis para optar al grado de Doctor en Literatura Latinoamericana, Universidad de Concepción, Concepción.

BARTHES, Roland (1984), El susurro del lenguaje. Más allá de la palabra y la escritura, Paidós, Barcelona.

BUTLER, Judith (2007), El género en disputa. El feminismo y la subversión de la identidad, Paidós, Barcelona.

CLÉMENT, Catherine y KRISTEVA, Julia (2000), Lo femenino y lo sagrado, [Trad. Maribel García Sánchez], Ediciones Cátedra, Madrid.

ESTEBAN, Roque (1978), Gabriela Anda por el mundo. Selección de prosas y prólogo de Roque Esteban Scarpa, Andrés Bello, Santiago de Chile.

FERNÁNDEZ, Luis (2010), Breve historia de la alquimia, Ediciones Nowtilus, Madrid.

FUNDACIÓN VIOLETA PARRA (2012), Violeta Parra obra visual, Ocho Libros y Fundación Violeta Parra, Santiago de Chile.

GENETTE, Gèrard (1989), Palimsestos La literatura en segundo grado [Trad. Celia Fernández Prieto], Taurus, Madrid.

GONZÁLEZ, Juan Pablo (2016), “A mi ciudad: Escucha crítica en la construcción simbólica del Santiago de 1980", Revista Musical Chilena, Vol. 70 (220): pp. 9-30.

GONZÁLEZ, Juan Pablo, et al., (2018), Tres discos autorales de Violeta Parra. Partituras completas, Ediciones Alberto Hurtado, Santiago de Chile, [En prensa].

HALL, Stuart (1997), “El trabajo de la representación”, pp. 1-55. En: HALL, Stuart (Eds.) "Representation: Cultural Representations and Signifaying Practices", [Trad. Elías Sevilla Casas], Sage Publications, London.

HERRERO, Víctor (2017), Después de vivir un siglo. Una biografía de Violeta Parra, Lumen, Santiago de Chile.

KRISTEVA, Julia (2001), Semiótica I, Fundamentos, Madrid.

MIRANDA, Paula (2005). Identidad nacional y poéticas identitarias: Gabriela Mistral, Vicente Huidobro, Pablo Neruda, Violeta Parra. Tesis doctoral en literatura con mención en literatura hispanoamericana y chilena, Universidad de Chile, Santiago. Disponible en: http:// repositorio.uchile.cl/bitstream/handle/2250/108865/Identidad-nacional-y-poeticas-identitariasGabriela-Mistral-Vicente-Huidobro-Pablo-Neruda-Violeta-Parra-1912-1967.pdf? sequence $=4 \&$ is Allowed $=\mathrm{y}$ visitado el 12/08/2018.

MOORE, Allan (2012), Song means: Analysing and Interpreting Recorded Popular Song, Ashgate Publishing, New York. 
MÜNNICH, Susana (1997), "El sentimiento de abandono en los textos de Violeta Parra y Gabriela Mistral”, Revista Atenea (475): pp. 125- 136.

PINOCHET, Carla (2007), Violeta Parra. Hacia un imaginario del mundo subalterno. Memoria para optar al título de Antropóloga Social, Universidad de Chile, Santiago.

PARRA, Violeta (1965), Poèsie Populaire des Andes [Trad. Franchita González-Battle], François Maspero, Paris.

PARRA, Violeta (1970), Décimas. Autobiografía en versos chilenos, Universidad Católica de Chile/ Pomaire, Santiago de Chile.

RODRÍGUEZ, Osvaldo (2015), Cantores que reflexionan. Notas para la historia personal de la Nueva Canción Chilena, [Edición al cuidado de Marisol García], Hueders: Santiago de Chile.

TORRES, Rodrigo (2004) “Cantar la diferencia. Violeta Parra y la Canción Chilena”, Revista Musical Chilena, 58 (201): pp. 53-73.

SÁEZ, Fernando (2010), La vida intranquila. Violeta Parra, Biografía Esencial, Ediciones Universidad de Chile, Santiago.

SAÍD, Edward (2007) Representaciones del intelectual, [Trad. Isidro Arias Pérez], Random House Mandadori, Barcelona.

SALINAS, Maximiliano (1991), Canto a lo divino y religión del oprimido en Chile, Rehue, Santiago de Chile.

SOUBLETTE, Gastón (1961), “El día de tu cumpleaños” [Reseña contraportada LP]. En: Violeta Parra: Toda Violeta Parra. El folklore de Chile, Vol. VIII, [LP], Odeon Santiago de Chile. Serie Estelar LDC 36344.

ŠTAMBUK, Patricia y BRAVO, Patricia (2011), Violeta Parra el canto de todos, Pehuén, Santiago de Chile.

VALDEBENITO, Lorena (2017), "What Type of Music did Violeta Parra Make? Her multiform, Musical, Autorship”. En: Vilches, Patricia (Ed.): Mapping Violeta Parra 's cultural landscapes, Palgrave Mcmillan, London.

\section{Discografía}

PARRA, Violeta. (1957), Violeta Parra canto y guitarra. El folklore de Chile, Vol. I, [LP], EMI Odeon, Santiago de Chile. LDC-36019.

PARRA, Violeta (1961), Toda Violeta Parra. El folklore de Chile, Vol. VIII, [LP], Odeon, Santiago de Chile. LDC-36344-Serie Estelar.

PARRA, Violeta (1965), Violeta Parra Recordando a Chile (Una Chilena en Paris), [LP], EMI-Odeon, Santiago de Chile. LDC-36533-Serie Estelar.

PARRA, Violeta (1971), Canciones reencontradas en Paris, [LP], Discoteca del Cantar Popular, DICAP/ La Peña de Los Parra, Santiago de Chile. DC-22.

PARRA, Isabel (1966), Isabel Parra, Demon, Santiago de Chile. LPD 0-26, 1966.

\section{NOTAS}

1. "Con seguridad Los manteles de Nemesio, en homenaje al pintor y su obra de ese tiempo" (Sáez, 2010: 101). 
2. Soublette señala "Esta canción fue compuesta a pedido de Enrique Bello, quien la víspera de su cumpleaños expresó el deseo de ser festejado con una canción de aniversario típicamente chilena, y dejar de mano el tan socorrido y horrible Happy Birthday. Violeta, al oír esto, dijo de inmediato: No seré yo quien se haga la sorda" (Soublette, 1961).

3. Según Sáez: "Allí conoció Violeta a Sergio Larraín [...] Violeta le compuso un solo de guitarra, $E l$ Joven Sergio" (Sáez, 2010: 95).

4. Según Herrero, Violeta Parra, compuso dos canciones a Alberto Zapicán, "El Albertío”, y “El hombre que yo más quiero" (Herrero, 2017: 487 y 488). Ésta última no llegó a grabarla, y por lo tanto sólo se conoce el texto, pero no su melodía [no sabemos si realmente tuvo música de Violeta], sin embargo, Isabel Parra la musicalizó, y esa es la versión que se conoce.

5. Carmen Luisa, señala que esa canción fue dedicada a Julio Escámez: "Vivíamos en la Universidad [de Concepción] juntos con Santos Chávez y Julio Escámez. ¿De ahí La muerte con anteojos? De ahí La muerte con anteojos? ... Terrible" (Rodríguez, 2015: 220). Sáez, también recuerda que Violeta compuso "Las manos de Julio, una canción para el pintor Escámez que los actores de se tiempo recuerdan haber escuchado varias veces, pero desaparecida dentro de la totalidad de su obra" (Sáez, 2010: 102). Además compuso a Escámez, las décimas: Engaños en Concepción "en este sentimiento ella ponía la misma pasión que en su trabajo" (Sáez, 2010: 103).

6. Ver contraportada LP, Violeta Parra Canto y Guitarra. El Folklore de Chile (1957).

7. Ver contraportada LP, Violeta Parra recordando a Chile, (1965).

8. Según Juan Pablo González, Violeta Parra, le habría dedicado esta canción a su hija Isabel, ver texto "Creadora de mundos y canciones", en: Tres discos autorales de Violeta Parra. Partituras completas, Santiago: Ediciones Alberto Hurtado, 2018 [En prensa].

9. Para Violeta Parra (1965) el canto a lo divino evoca temáticas celestiales, basadas en la biblia, mientras que el canto a humano, evoca otras temáticas basadas en temas más terrenales, como "versos por ponderación", "versos por el mundo al revés", versos por sabiduría", entre otros. Según Salinas (1991), la expresión a lo divino puede dividirse en: "poesía bíblica y poesía ritual" (Salinas, 1991: 41).

10. Ver trabajo más extenso sobre la autoría de Violeta Parra en, Valdebenito (2018).

11. En canciones como: "La muerte con anteojos"; "El rin del angelito"; "Gracias a la vida", entre otras.

12. No nos referimos al "Canto a lo divino", sino que a lo divino como categoría de análisis, en tanto es una alusión relevante que articula el texto literario en diálogo con el texto musical.

13. Ver lo alusivo a temas sobre religiosidad popular y lo divino en su poesía en las: Décimas (1970) y las alusiones religiosas en sus obras visuales en: Obra Visual de Violeta Parra (2012).

14. Cabe aclarar que en la categorización de González, se valora la autoría de cantautora de Violeta Parra, pero no tanto la de cantora o folclorista que Violeta venía desarrollando desde mucho antes, en canciones como "La jardinera" o "Parabienes al revés" (canciones que Violeta crea tomando como base estructuras o formas muy definidas de la tradición, como lo son la tonada y el parabién respectivamente), o en canciones como: "Versos por la niña muerta" o "La muerte con anteojos" (canciones con temáticas a lo humano y con una sonoridad del canto a lo poeta), y de compositora en el disco Composiciones para guitarra (1957).

15. La transcripción musical de las canciones referenciadas en este artículos son nuestras.

16. Ver Johanes Paulus II, "Fides et Ratio. A los obispos de la Iglesia Católica sobre las relaciones entre Fe y Razón". Disponible en https://web.archive.org/web/20090720021225/http:// www.vatican.va/edocs/ESL0036/_INDEX.HTM visitado el 03/08/2018. 
17. Ver críticas sobre la categoría de "Madre" en Mistral, desde la oficialidad chilena, en Miranda (2005). Según la autora: "El erigirla como la gran madre entonces no quiere decir que ella lo sea, o que lo sea en los términos que el receptor (chileno) se lo está pidiendo: una gran madre de la patria que se instala al lado de la Virgen María y del Padre de la patria. No, ella será entre otras muchas cosas una mamá y a su manera, alejándose mucho del uso social que se ha hecho del asunto en los discursos gritones del nacionalismo (Miranda, 2005: 68).

18. Nuestra visión sobre Violeta Parra y Gabriela Mistral contrasta con la de Münnich, por quien estas dos mujeres son analizadas como íconos femeninos de lo marginal, la pobreza, la clase campesina, sin embargo, cabe distinguir las problemáticas sobre las cuales se ocupan Parra y Mistral, y su pasado campesino, de la versión cristalizada y esencial que nos ofrece la autora, dejando de lado aspectos importantes de gran nivel artístico e intelectual alcanzados por estas chilenas, como también las problemáticas religiosas, filosóficas y políticas que se transforman en un verdadero corpus desde el cual erigen, no sólo su obra, sino que también su pensamiento artístico. Mientras para Münnich: “es comprensible que la música de Violeta Parra no encuentre eco en la población chilena. Puede decirse que todo lo que escribió está traspasado de amor por el pobre y preocupación por el pobre. Semejante lo que ocurre con Gabriela Mistral. Una de las presencias más notorias en sus textos es la pobreza. La familia pobre, la mujer popular abandonada a la miseria, el niño desamparado, son temas frecuentes de su poesía. Y no si están presentes objetivamente, sino que la poeta se identifica con estos pobres" (Münnich, 1997: 28).

\section{RESÚMENES}

Este artículo se propone analizar y describir de qué manera se produce una intertextualidad literaria y musical, y una representación de lo femenino en dos canciones concebidas como homenajes musicales de Violeta Parra a dos mujeres: Valentina Tereshkova y Gabriela Mistral.

Analizaremos el modo en que la noción de "vida", en la canción "Qué vamos a hacer" (Ayúdame Valentina), y noción de "muerte", en la canción "Versos por despedida a Gabriela Mistral", son dos alusiones que marcan un sentido enunciativo particular. Así, revisaremos cómo se produce una intertextualidad entre lo divino, como primera categoría de análisis que dialoga desde un plano místico/religioso, con lo femenino, como segunda categoría, que dialoga desde un plano de género, a partir de cómo aparece representado.

This article aims to analyze and describe how a literary and musical intertextuality is produced, and a representation of the feminine in two songs conceived as musical tributes by Violeta Parra to two women: Valentina Tereshkova and Gabriela Mistral. We will analyze the way in which the notion of "life", in the song "Qué vamos a hacer" (Ayúdame Valentina), and notion of "death", in the song "Versos por despedida a Gabriela Mistral", are two allusions that mark a particular enunciative sense. Thus, we will review how an intertextuality occurs between the divine, as the first category of analysis that dialogues from a mystical / religious plane, with the feminine, as a second category, which dialogues from a gender plane, from how it is represented. 
ÍNDICE

Keywords: Musical tribute, intertextuality, representation, the femenine, the divine

Palabras claves: Homenaje musical, intertextualidad, representación, lo femenino, lo divino

\section{AUTOR}

\section{LORENA VALDEBENITO CARRASCO}

Doctora en Musicología

Universidad Alberto Hurtado

lvaldebe(a)uahurtado.cl 